\title{
Resistant Hypoglycaemia - A Unique Presentation of Congenital Dengue
}

\author{
Narendra Rai ${ }^{1}$, Neha Thakur ${ }^{2 *}$ and Divya Pandey ${ }^{1}$ \\ ${ }^{1}$ Department of Pediatrics, Chandan Hospital, India \\ ${ }^{2}$ Department of Pediatrics, Dr. Ram Manohar Lohia Institute of Medical Sciences, India
}

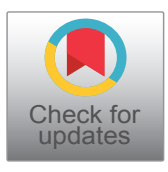

*Corresponding author: Neha Thakur, Department of Pediatrics, Dr. Ram Manohar Lohia Institute of Medical Sciences, Lucknow, Uttar Pradesh, India, Tel: +917607804654

\begin{abstract}
Vertical transmission of dengue is uncommonly reported. There have been occasional case reports of congenital dengue with thrombocytopenia and myocarditis. This is the first case report of refractory hypoglycaemia in congenital dengue. We are reporting a case of congenital dengue in a primigravida who developed dengue fever in last trimester of pregnancy. She underwent an emergency caesarean section in view of decreased foetal movements. Post-operative she developed post-partum haemorrhage and pleural effusion. Baby was admitted in neonatal intensive care unit in view of respiratory distress and low birth weight. On day 2 of life child developed hypoglycaemia and sudden onset of severe thrombocytopenia requiring glucose infusion and platelet transfusions. Dengue NS1 antigen was positive both in mother and child. Sepsis screen was negative and metabolic profile of the child was normal. The child recovered gradually and was discharged on day 7 of life. Early diagnosis of dengue in pregnancy helps in better management of mother and child. This case also presents hypoglycaemia as a unique manifestation of congenital dengue which nearly lasted for a week.
\end{abstract}

\section{Keywords}

Congenital, Dengue, Hypoglycaemia, Thrombocytopenia

\section{Introduction}

Dengue fever is an arboviral disease transmitted by Aedes mosquito. WHO has defined it as an acute febrile illness associated with two or more of the following signs or symptoms: intense headache, retro-orbital pain, myalgia, arthralgia, skin rash, leucopenia and hemorrhagic manifestations [1]. Primary mode of transmission between humans involves mosquito vectors. Very little evidence of vertical transmission from mother to child with dengue infection during pregnancy has been reported [2-5]. We are reporting a unique presentation of resistant hypoglycaemia in a newborn baby who had developed congenital dengue infection. Dengue-related hypoglycaemia has not been reported previously. This is perhaps the first time resistant hypoglycaemia is being reported in the setting of congenital dengue.

\section{Case Presentation}

A single late preterm ( 36 weeks) male baby weighing 20855 gm was delivered by Emergency Caesarean Section to a 29-years-old primigravida mother. Baby did not cry immediately after birth had an APGAR score of 4, 7 at 1 and 5 minutes respectively. He received initial steps of resuscitation along with bag and mask ventilation for 30 seconds. Post-resuscitation baby had respiratory distress hence was admitted to level 3 neonatal intensive care unit (NICU). On admission in NICU baby was grunting and had vitals of Heart rate $143 / \mathrm{min}$, respiratory rate of $66 / \mathrm{min}$, temp $98.6^{\circ} \mathrm{F}, \mathrm{SpO}_{2}$ at room air was $98 \%$, CRT < 3 sec and routine blood sugar was $42 \mathrm{mg} / \mathrm{dl}$. Baby's rest of the systemic examination was normal. He did not have any congenital anomalies. On admission, baby was given oxygen by nasal prongs, IV fluid and first line IV antibiotics. Investigations showed a negative sepsis screen with a CRP of $1.5 \mathrm{mg} / \mathrm{dl}$ (Normal: $<6 \mathrm{mg} / \mathrm{dl}$ ). Blood and urine cultures were sterile. Complete blood count showed a haemoglobin level of $15.5 \mathrm{mg} / \mathrm{dl}$ and a platelet count of $2.2 \mathrm{~L} / \mathrm{cumm}$. On day 2 of admission the child's general condition deteriorated with appearance of petechial rashes and development of resistant hypoglycaemia. The platelet count dropped suddenly to

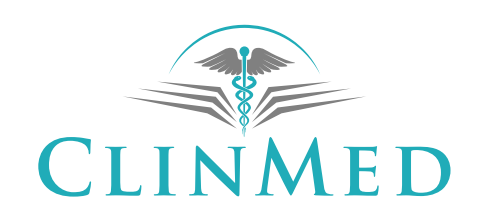

INTERNATIONAL LIBRARY 
11000/cumm. His liver function test and blood coagulation profile were normal.

Antenataly mother was running fever with chills for four days prior to delivery. Her Dengue NS1 Ag test was positive. An emergency caesarean section was done in view of decreased foetal movements and non-reassuring NST. Post-delivery she had severe post-partum haemorrhage due to thrombocytopenia. Dengue NS1 Ag of baby, sent on day 2 of admission was also positive. Baby was given platelet transfusion and the glucose infusion rate was gradually increased to $12.5 \mathrm{mg} / \mathrm{dl}$ to manage thrombocytopenia and hypoglycaemia respectively. Still the blood sugar level was found to be low. Hence the child was worked up for resistant hypoglycaemia. Serum insulin level was found to be low $2.15 \mathrm{mU} / \mathrm{L}$ (2.6$37.6)$ and serum cortisol level was normal $12.53 \mathrm{mcg} /$ dl (3.5-45). TSH was normal. On day 4 of admission the baby spontaneously started improving, the platelet values started to increase and the blood sugar levels stabilised. Child was started on oral feeds, gradually weaned of IV fluid and was put on breast feeding. The baby was finally discharged on day 7 of life with diagnosis of congenital dengue with refractory hypoglycaemia and severe thrombocytopenia.

\section{Discussion}

Dengue is an acute mosquito borne viral infection first isolated in India in 1944. Since then it is spreading into newer areas newer population and increasing in magnitude with every epidemic. Dengue fever during pregnancy is a mounting issue in Southeast Asia; particularly India however, the data on its clinical manifestations and adverse effects on mothers and neonates remains inadequate. A study in Northern India found a significant high percentage of pregnant female to be having dengue during antenatal period [6,7]. Vertical transmission of dengue is very infrequently reported hence very little is known about this mode of infection [8]. A systematic review of dengue in pregnancy had shown antenatal infection can lead to preterm and low birth weight babies [9]. There are occasional case reports of congenital dengue with microcephaly [10], myocarditis [11], thrombocytopenia [12,13]. There has not been a single case report of refractory hypoglycaemia in congenital dengue infection until now. Vertically transmitted dengue virus infections have an incubation period of 1-11 days after birth, with an average of four days and the signs and symptoms generally last for less than a week [14]. In our case mother had dengue infection just days prior to delivery. The baby became symptomatic on day 2 of life. The new born had a stormy post neonatal period with refractory hypoglycaemia and severe thrombocytopenia requiring platelet transfusion and glucose infusion. This clinical picture mimics neonatal sepsis and would have been managed in those lines had the diagnosis of maternal dengue been not done. Mother too had a stormy post-natal course in intensive care unit with severe post-partum haemorrhage and pleural effusion with respiratory distress. Both mother and child responded to treatment and were discharged on $7^{\text {th }}$ post-natal day. This case highlights the importance of early diagnosis of dengue in febrile pregnant females particularly in endemic countries like India for better outcome and management of mother child duo. This case also presents a unique presentation of congenital dengue in the form of refractory hypoglycaemia which lasted till day 5 of life in a child with congenital dengue infection.

\section{Summary}

Congenital dengue presenting as refractory hypoglycaemia in a 2-year-old late preterm infant delivered to primigravida mother who had dengue hemorrhagic fever.

\section{Author Contribution}

Dr. Neha, Dr. Narendra and Dr. Divya drafted the initial manuscript, and reviewed the literature and revised the manuscript. All authors have approved the final manuscript as submitted and agree to be accountable for all aspects of the work.

\section{Author Declarations}

\section{Funding}

Nil.

\section{Consent}

Not required.

\section{Conflict of interest}

None.

\section{References}

1. Carroll ID, Toovey S, Van Gompel A (2007) Dengue fever and pregnancy - a review and comment. Travel Med Infect Dis 5: $183-188$.

2. Basurko C, Matheus S, Hilderal H, Everhard S, Restrepo $\mathrm{M}$, et al. (2018) Estimating the risk of vertical transmission of dengue: A prospective study. Am J Trop Med Hyg 98: 1826-1832.

3. Mazarin N, Rosenthal JM, Devenge J (2014) Mother infant dengue transmission during the 2009-2010 dengue epidemic: Report of four cases. Arch Pediatr 21: 745-749.

4. Waggoner JJ, Gresh L, Vargas MJ, Ballesteros G, Tellez Y, et al. (2016) Viremia and clinical presentation in nicaraguan patients infected with zika virus, chikungunya virus, and dengue virus. Clin Infect Dis 63: 1584-1590.

5. Sinhabahu VP, Sathananthan R, Malavige GN (2014) Perinatal transmission of dengue: A case report. BMC Res Notes 7: 795.

6. Basurko C, Carles G, Youssef M, Guindi WEL (2009) Maternal and foetal consequences of dengue fever during pregnancy. European Journal of Obstetrics \& Gynecology and Reproductive Biology 147: 29-32.

7. Singla N, Arora S, Goel P, Chander J, Huria A (2015) Den- 
gue in pregnancy: An under-reported illness, with special reference to other existing co-infections. Asian Pac J Trop Med 8: 206-208.

8. Maroun SLC, Marliere RCC, Barcellus RC, Barbosa CN, Ramos JRM, et al. (2008) Case report: Vertical dengue infection. J Pediatr 84: 556-559.

9. Pouliot SH, Xiong X, Harville E, Paz-Soldan V, Tomashek KM, et al. (2010) Maternal Dengue and Pregnancy Outcomes: A Systematic Review. Obstet Gynecol Surv 65: 107-118.

10. Alallah J, Mohtisham F, Saidi N, Almehdar A, Anees A, et al. (2020) Congenital dengue in a Saudi neonate: A case report. J Neonatal Perinatal Med 13: 279-282.
11. Sharma R, Parwal N, Kumar N, Puliyel JM (2012) Congenital dengue and myocarditis: A case report and systematic review of literature. Infectious Diseases in Clinical Practice 20: $180-181$.

12. Thomas J, Thomas P, George CR (2017) Neonatal dengue. Int J Contemp Pediatr 4: 2234-2246.

13. Morgan-Ortiz F, Rodríguez-Lugo SM, León-Gil MS, Gaxiola-Villa M, Martínez-Félix NS, et al. (2014) Hemorrhagic dengue and vertical transmission to the newborn: A case report and literature review. Ginecol Obstet Mex 82: 401-409.

14. Sirinavin $S$, Nuntnarumit $P$, Supapannachart $S$, Boonkasidecha S, Techasaensiri C, et al. (2004) Vertical dengue infection: Case reports and review. Pediatr Infect Dis J 23: 1042-1047. 